${ }^{1}$ Department of Nephrology, Transplantology and Internal Medicine, Medical University of Gdańsk, Poland

${ }^{2}$ Department of Hypertension and Diabetology, Medical University of Gdańsk, Poland

${ }^{3}$ Department of Radiology, Medical University of Gdańsk, Poland

${ }^{4}$ Department of General, Endocrine and Transplant Surgery, Medical University of Gdańsk, Poland

${ }^{5}$ Transplantation Institute, University of Chicago

${ }^{6}$ Cell and Tissue Bank, University Clinical Centre in Gdańsk, Poland

${ }^{7}$ Regional Transplant Coordination Center, University Clinical Centre in Gdańsk, Poland

${ }^{8}$ Laboratory for Cell and Tissue Banking and Transplantation CellT, Gdańsk, Poland

${ }^{9}$ Department of Medical Immunology, Medical University of Gdańsk, Poland

\title{
Pancreatic islet transplantation in a simultaneous pancreas and kidney transplant recipient - a case report
}

\section{ABSTRACT}

Beta cell replacement allows for adequate blood glucose control, reduced progression or even reversal of microvascular complications, and improves the quality of life. Simultaneous pancreas and kidney transplantation is the best therapeutic option for patients with type 1 diabetes and end-stage renal disease resulting from diabetic nephropathy. However, when pancreas transplantation is contraindicated or unavailable, pancreatic islet transplantation is an alternative minimally invasive procedure. We report a patient after earlier simultaneous kidney and pancreas transplantation with a failed pancreas graft, and no option for pancreas retransplantation. In this patient pancreatic islet transplantation was performed. The latter resulted in an improved blood glucose control, restoration of hypoglycaemia awareness, and improved quality of

Address for correspondence:

dr hab. n. med. Justyna Gołębiewska

Klinika Nefrologii, Transplantologii i Chorób Wewnętrznych

Gdański Uniwersytet Medyczny

ul. Dębinki 7, 80-952 Gdańsk

Phone: 583492558

Fax: 583492551

e-mail: jgolebiewska@gumed.edu.pl

Translation: dr n. med. Piotr Jędrusik

Clinical Diabetology 2020, 9; 5: 338-343

DOI: $10.5603 /$ DK.2020.0034

Received: 26.03.2020

Accepted: 12.06.2020 life with stable good function of the kidney allograft. (Clin Diabetol 2020; 9; 5: 338-343)

Key words: pancreatic islet transplantation, severe hypoglycaemia

\section{Case report}

We report a 41-year-old patient with type 1 diabetes since the age of 9 , with chronic kidney disease (CKD) stage G5D due to diabetic nephropathy. At 32 years of age, half a year after entering a chronic haemodialysis programme, the patient underwent simultaneous kidney and pancreas transplantation in the Department of General, Vascular, and Transplant Surgery, Medical University of Warsaw. At the time of kidney and pancreas transplantation, the patient was already blind due to diabetic retinopathy. No macroangiopathic complications were noted. Immediately after kidney and pancreas transplantation, the patient required reoperation for hematoma evacuation, followed by drainage of an infected fluid collection. Despite complications, the patient did not require insulin support since the transplantation. At about 3 years after the transplantation, worsening followed by complete loss of the transplanted pancreas function was observed, with the need to reinitiate insulin, and a stable good function of the transplanted kidney with serum creati- 
nine levels of about $0.9 \mathrm{mg} / \mathrm{dL}$. The patient remained under the care of the Transplantation Clinic at the Institute of Transplantology in Warsaw for 7 years, and then decided to transfer the care of the Transplantation Unit at the University Clinical Centre in Gdańsk.

At the time of care transition, blood glucose control was clearly unsatisfactory despite optimized therapy with multiple daily injections of insulin analogues glulisine and glargine, with haemoglobin $\mathrm{A}_{1 \mathrm{c}}\left(\mathrm{HbA}_{1 \mathrm{c}}\right)$ levels of $7.7-8.7 \%$. The daily insulin dose was about 40-50 units. During continuous glucose monitoring (iPRO ${ }^{\mathrm{TM}} 2$, Medtronic), the mean blood glucose level was $207 \pm 76 \mathrm{mg} / \mathrm{dL}$ (Figure 1A). Blood glucose level was within the target range (70-180 $\mathrm{mg} / \mathrm{dL}$ ) for $42 \%$ of the time, and below the target range for $2 \%$ of the time. In addition, hypoglycaemia unawareness with the Gold score of 5 was an additional problem. The patient had large blood glucose level excursions with recurrent severe hypoglycaemia episodes during the last year. For this reason, the patient was offered pancreatic islet transplantation at Gdańsk Transplantation Center. The patient, who suffered from surgical complications following the initial pancreas transplantation, did not consent to another major surgery.

Despite a history of hepatitis $C$, neither viral replication nor evidence of hepatic damage were noted at the time of evaluation for pancreatic islet transplantation. Since simultaneous kidney and pancreas transplantation, the patient was receiving three immunosuppressive drugs: prednisone, tacrolimus and mycophenolate sodium. His body weight was $56.5 \mathrm{~kg}$, and his body mass index (BMI) was $20.8 \mathrm{~kg} / \mathrm{m}^{2}$. Anti-HLA antibody testing was negative (Luminex Screen, Luminex Single Antigen).

In addition to establishing the indications, the evaluation for pancreatic islet transplantation included the assessment of the severity of diabetes complications, technical feasibility of the procedure, exclusion of potential infection foci, screening for common malignancies and immunological evaluation.

On October 27, 2018, the patient underwent transplantation of 374,940 islet equivalents (IEQ), or 6,637 IEQ per kg of body mass. The donor was a 26 -year-old male who died due to craniocerebral trauma, with blood group 0 consistent with the blood group of the patient. Human leukocyte antigen (HLA) compatibility included only one matching group A antigen (5 mismatches), but there were no repeated mismatches with the pancreas and kidney donor. The CDC and flow cytometry crossmatch testing was negative. Thymoglobulin and etanercept were used for induction. Overall, the patient received $6 \mathrm{mg} / \mathrm{kg}$ of Thymoglobulin and $125 \mathrm{mg}$ of etanercept in fractionated doses over
10 days. This is an off-label indication for etanercept. Tacrolimus and mycophenolate sodium were continued. The tacrolimus dose was transiently increased to achieve the serum trough level of $10-14 \mu \mathrm{g} / \mathrm{L}$, mycophenolate sodium was increased to $720 \mathrm{mg}$ twice daily, and prednisone was continued ( $5 \mathrm{mg} / \mathrm{d}$ ). Pancreatic islet transplantation involved infusion of pancreatic islets in a special solution containing human albumin and heparin. The infusion was performed through a catheter introduced percutaneously and transhepatically by an interventional radiologist to the main branch of the portal vein under ultrasonographic and fluoroscopic guidance. Following the procedure, a transient increase in transaminase activity, mild anaemia, and an increase in anti-GAD level from $21.86 \mathrm{IU} / \mathrm{mL}$ before transplantation to $1346.86 \mathrm{IU} / \mathrm{ml}$ (normal values $<10 \mathrm{IU} / \mathrm{mL}$ ) at 14 days after transplantation were observed, which was interpreted at this stage as an immunologic reaction to islet infusion and plasmapheresis was performed, resulting in a reduction of anti-GAD level to $283.18 \mathrm{IU} /$ $/ \mathrm{mL}$. Follow-up Doppler ultrasound of the portal system did not show evidence of thrombosis or the presence of a hematoma adjacent to the liver. The patient was given insulin to protect the pancreatic islets from excessive metabolic stimulation during islet engraftment into the hepatic tissue. Over several days, the daily insulin dose was gradually reduced to about 26 units (reduction by about $50 \%$ ) and significantly lower blood glucose levels were observed. At 75 days after pancreatic islet transplantation, considered the end of the islet engraftment period, a follow-up CGM (iPRO ${ }^{\mathrm{TM}_{2}}$, Medtronic) was performed, showing a reduction in the variation of blood glucose levels, as evidenced by a reduction of the standard deviation of blood glucose levels from \pm 76 to $\pm 28 \mathrm{mg} / \mathrm{dL}$. The proportion of time with blood glucose levels $>180 \mathrm{mg} / \mathrm{dL}$ was reduced from $56 \%$ to $2 \%$, and the proportion of time with low blood glucose levels ( $<70 \mathrm{mg} / \mathrm{dL}$ ) was reduced from $2 \%$ to $0 \%$ and no episode of severe hypoglycaemia was noted. The patient reported that the threshold of hypoglycaemia awareness increased to $50 \mathrm{mg} / \mathrm{dL}$. The blood glucose level was within the target range (70-180 mg/dL) for $98 \%$ of the time (Figure $1 \mathrm{~B}$ ). $\mathrm{HbA}_{1 \mathrm{c}}$ level was $6.7 \%$. Other laboratory testing at that time confirmed stable good function of the transplanted kidney, normal complete blood count parameters, and absence of anti-HLA antibodies that would suggest humoral rejection.

During the next months after pancreatic islet transplantation, a gradual worsening of blood glucose control was observed, with an increase in $\mathrm{HbA}_{1 \mathrm{c}}$ level to 7.1\%. During CGM (iPRO ${ }^{\mathrm{TM}_{2}}$, Medtronic) at 9 months after islet transplantation, blood glucose level was within the target range $(70-180 \mathrm{mg} / \mathrm{dL})$ for $82 \%$ of the 
Table 1. Haemoglobin $\mathrm{A}_{1 \mathrm{c}}\left(\mathrm{Hb}_{1 \mathrm{c}}\right)$ and peptide $\mathrm{C}$ levels and daily insulin doses at various time points

\begin{tabular}{|c|c|c|c|c|}
\hline & $\begin{array}{c}\mathrm{HbA}_{1 \mathrm{c}} \\
\text { level }\end{array}$ & $\begin{array}{c}\text { Fasting peptide C } \\
\text { level }\end{array}$ & $\begin{array}{l}\text { Peptide C level following } \\
\text { mixed meal stimulation }\end{array}$ & $\begin{array}{l}\text { Daily insulin } \\
\text { dose }\end{array}$ \\
\hline Before kidney and pancreas transplantation & No data & $0 \mathrm{ng} / \mathrm{ml}$ & - & 64 units \\
\hline 1 year after kidney and pancreas transplantation & No data & No data & No data & 0 units \\
\hline 3 years after kidney and pancreas transplantation & No data & No data & $1.36 \mathrm{ng} / \mathrm{mL}$ & 26 units \\
\hline 8 years after kidney and pancreas transplantation & $8.7 \%$ & $0 \mathrm{ng} / \mathrm{mL}$ & $0 \mathrm{ng} / \mathrm{mL}$ & $40-50$ units \\
\hline 75 days after first pancreatic islet transplantation & $6.7 \%$ & $0.31 \mathrm{ng} / \mathrm{mL}$ & $2.05 \mathrm{ng} / \mathrm{mL}$ & 26 units \\
\hline 9 months after first pancreatic islet transplantation & $7.1 \%$ & $0.38 \mathrm{ng} / \mathrm{mL}$ & $1.52 \mathrm{ng} / \mathrm{mL}$ & 26 units \\
\hline 75 days after second pancreatic islet transplantation & $6.1 \%$ & $1.43 \mathrm{ng} / \mathrm{mL}$ & $9.66 \mathrm{ng} / \mathrm{mL}$ & 15 units \\
\hline 9 months after second pancreatic islet transplantation & $5.9 \%$ & $1.42 \mathrm{ng} / \mathrm{mL}$ & No data & $12-13$ units \\
\hline
\end{tabular}

time but the proportion of time with blood glucose level $>180 \mathrm{mg} / \mathrm{dL}$ increased from $2 \%$ to $13 \%$. Also, the proportion of time with low blood glucose level ( $<70 \mathrm{mg} / \mathrm{dL}$ ) increased to $5 \%$ (Figure $1 \mathrm{C}$ ).

A decision was made to repeat pancreatic islet transplantation from another donor. On September 3,2019 , the patient underwent transplantation of 366,134 IEQ, or 6,356 IEQ per kg of body mass. This time, the donor was a 20-year-old male who died due to a subarachnoid haemorrhage, with blood group 0 consistent with the blood group of the patient. HLA compatibility included only one matching group $A$ antigen (5 mismatches), but no repeated mismatches with the kidney and pancreas donor and the previous pancreatic islet donor were present. The CDC and flow cytometry crossmatch testing was negative. Basiliximab and etanercept were used for induction. The patient received the standard dose of basiliximab, two $20 \mathrm{mg}$ doses, and $125 \mathrm{mg}$ of etanercept in fractionated doses over 10 days. Tacrolimus, mycophenolate sodium and prednisone were continued.

Over several days, the daily insulin dose was gradually reduced to about 20 units (the dose was 40-50 units per day before the first transplantation). At the end of the islet engraftment period at 75 days, when the daily insulin requirement was 12-14 units, another follow-up CGM (iPRO ${ }^{\mathrm{TM}} 2$, Medtronic) recording was performed. The standard deviation of blood glucose levels was $\pm 37 \mathrm{mg} / \mathrm{dL}$. The proportion of time with blood glucose levels $>180 \mathrm{mg} / \mathrm{dL}$ was $10 \%$, and the proportion of time with low blood glucose levels ( $<70 \mathrm{mg} / \mathrm{dL}$ ) was reduced to $1 \%$. Blood glucose level was within the target range (70-180 $\mathrm{mg} / \mathrm{dL}$ ) for $89 \%$ of the time (Figure 1D). $\mathrm{HbA}_{1 \mathrm{c}}$ level was $6.1 \%$.

Currently, at 19 months since the initial pancreatic islet transplantation, the daily insulin requirement is 12-13 units, and $\mathrm{HbA}_{1 \mathrm{c}}$ level is $5.9 \%$ (Table 1). No episodes of severe hypoglycaemia have been noted. No significant complications have occurred since the initial pancreatic islet transplantation, either procedure-related or resulting from the immunosuppressive therapy. The quality of life of both the patient and his family has improved significantly. The patient has become more active and has been involved in the community as a member of the local community board.

\section{Discussion}

Beta cell transplantation, either as the solid-organ pancreas or isolated pancreatic islets, is currently the only method to restore physiologic secretion of endogenous insulin. Pancreatic islet transplantation to the liver via the portal vein system is a safe minimally invasive alternative to transplantation of the solid-organ pancreas [1]. Due to still suboptimal islet isolation techniques, the efficacy of this process is limited and the number of islets yielded usually corresponds to $30-50 \%$ of islets in the whole pancreas. Thus, a single recipient typically requires two or three islet infusions from various donors to provide a satisfactory and relatively durable metabolic improvement. Achieving the state of insulin independence, although possible, particularly with repeated islet infusions from several donors, is not the major goal of pancreatic islet transplantation. The main goals include stabilization of the disease course, minimizing the risk of chronic complications, and a significant reduction or even elimination of the risk of life-threatening severe hypoglycaemia episodes.

For this reason, the indication for islet transplantation as the minimally invasive alternative to solidorgan pancreas transplantation is type 1 diabetes with recurrent severe hypoglycaemia episodes in patients with hypoglycaemia unawareness, i.e. unawareness of pathologically low blood glucose levels $<70 \mathrm{mg} / \mathrm{dL}$ without prodromal symptoms such as hunger and symptoms resulting from adrenergic (tremor, palpitations, anxiety) and cholinergic system (sweating, paresthesiae) activation [2]. According to the 2018 International Pancreas and Islets Transplant Association/ 


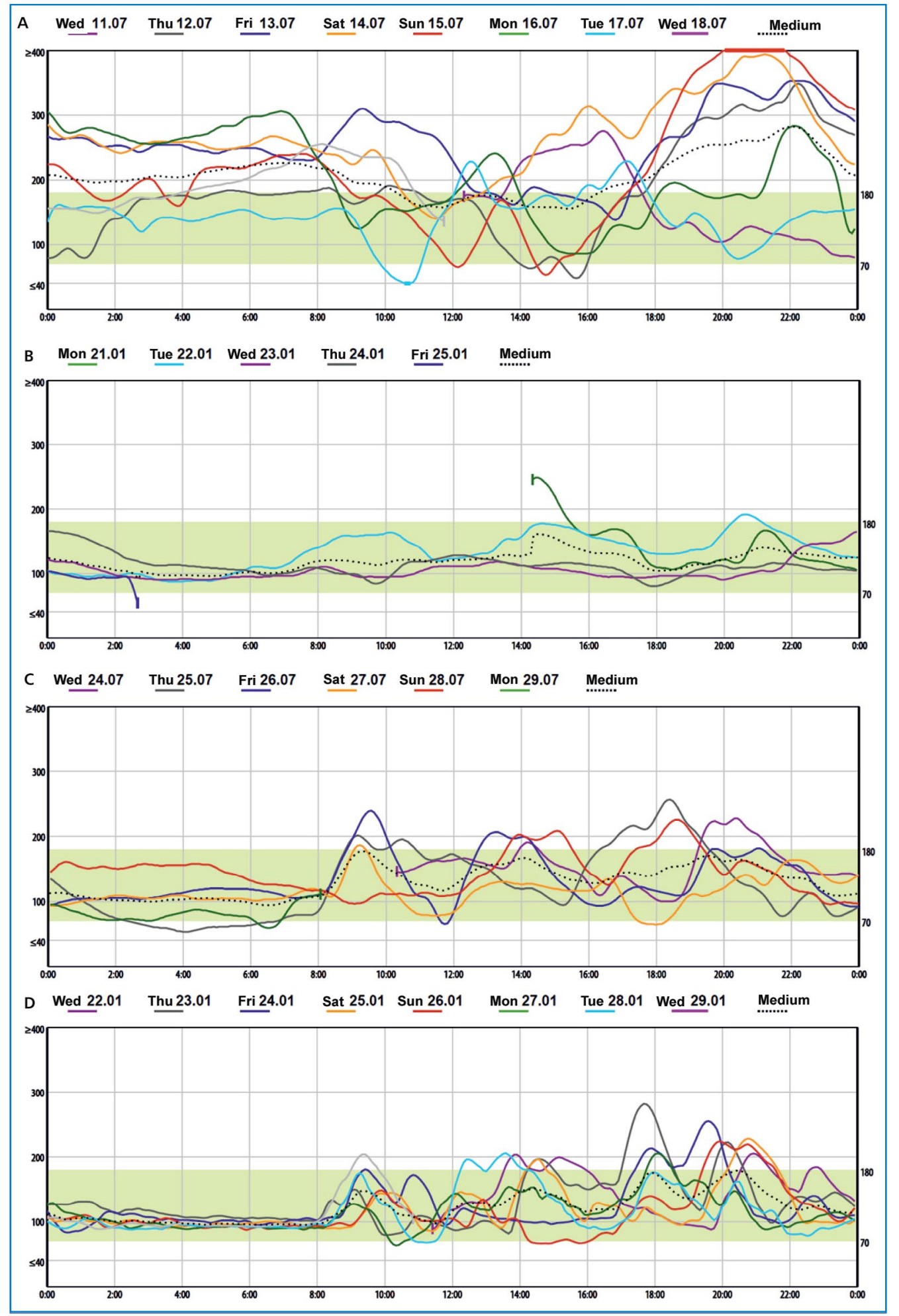

Figure 1. Continuous glucose monitoring: A. before pancreatic islet transplantation; B. 75 days after pancreatic islet transplantation; C. 9 months after pancreatic islet transplantation; D. 75 days after the second pancreatic islet transplantation

/European Pancreas and Islets Transplant Association (IPITA/EPITA) guidelines, indications for beta cell transplantation in patients with type 1 diabetes include at least one documented severe hypoglycaemia episode in the last year, the proportion of low glucose levels $(<54 \mathrm{mg} / \mathrm{dL}) \geq 5 \%$ during CGM, or hypoglycaemia unawareness with the Gold score of $\geq 5$ along with evidence of poor blood glucose level control, such as 
$\mathrm{HbA}_{1 \mathrm{c}}$ level > 7.5-8.0\%, and excessive blood glucose excursions, such as the CGM coefficient of variation $\geq$ $30 \%$ or the standard deviation of blood glucose level during CGM $\geq 40 \mathrm{mg} / \mathrm{dL}$ [3]. In the reported patient, hypoglycaemia unawareness with the Gold score of $\geq$ $5, \mathrm{HbA}_{1 \mathrm{c}}$ level of $8.3 \%$, the standard deviation of blood glucose level during CGM of $\pm 76 \mathrm{mg} / \mathrm{dL}$, and the CGM coefficient of variation of $37 \%$ were present.

It was shown that pancreatic islet transplantation was associated with an improvement in the quality of life only in those patients who reported hypoglycaemia unawareness and severe hypoglycaemia episodes requiring the help of other persons. In patients with blood glucose excursions that did not impair normal daily activities, no improvement in the quality of life was seen $[4,5]$. Thus, the key to successful patient selection for pancreatic islet transplantation, similarly to other procedures, are the realistic expectations of both the patient and the referring physician.

The patient selection process also includes the assessment of procedure feasibility. This includes evidence of liver damage, synthetic function of the liver, presence of portal hypertension or hepatic lesions, such as arteriovenous anastomoses that might impair pancreatic islet infusion to the portal system or islet integration within the hepatic tissue. Currently available evidence indicates that the liver is the optimal site for pancreatic islet transplantation.

Transplantation of pancreatic islets from a deceased donor is associated with antigenic incompatibility, thus necessitating immunosuppressive therapy. For this reason, the potential recipient must be evaluated for the presence of overt and latent infection foci and screened for the most common malignancies. Any abnormalities found constitute a contraindication only until the problem is resolved, e.g., a patient may receive pancreatic islets after oral cavity sanitation or after the infected ulcers of a diabetic foot are appropriately treated.

The standard immunosuppression regimen for pancreatic islet transplantation includes induction and maintenance therapy. Polyclonal antibodies resulting in lymphocyte depletion (thymoglobulin) or monoclonal antibodies against interleukin-2 receptor are most commonly used for the induction therapy. Due to an inflammatory reaction that accompanies islet infusion, this is combined with TNF- $\alpha$ blockade using etanercept $[6,7]$, an off-label indication for the latter drug.

If the patient already received a kidney or other organ transplant (e.g., heart, lung, liver) and is on chronic immunosuppressive therapy, the indications for pancreatic islet transplantation may be extended to patients with poor metabolic control only, without the history of severe hypoglycaemia, as the patient is only subjected to a minimally invasive islet transfusion which is associated with a minimal risk of complications $[7,8]$. The indications have been discussed in detail in a review paper that has been published in the same issue of the journal.

Liver bleeding may occur in $10 \%$ of patients, which usually requires a blood transfusion only, and only $1 \%$ of patients require surgical treatment. Portal vein thrombosis occurs rarely, in about $3 \%$ of patients, usually segmentally in small portal system branches, has no clinical significance and typically resolves with it anticoagulation without clinical sequelae.

In the reported case, pancreatic islet transplantation was performed due to failure of earlier pancreas transplantation and a high risk of severe hypoglycaemia despite optimized drug treatment with multiple insulin analogue injections. Following pancreas transplantation, the patient required reoperation due to surgical complications. Although the kidney and the pancreas were transplanted simultaneously from the same donor, the pancreas transplant functioned for a significantly shorter time than the kidney transplant. The patient was insulinindependent for only 3 years, and thereafter metabolic control was not satisfactory despite increasing insulin doses, with recurrent severe hypoglycaemia episodes. Pancreas transplantation is a major surgery with a significant risk of severe surgical complications and treatment failure. If it is successful, the patient may remain insulin-independent for many years. In the reported case, despite successful treatment of complication, the transplanted pancreas function had a limited duration. It is not clear what mechanism was responsible for the loss of the pancreas allograft function. As the function of the transplanted kidney was stable and good, alloagression is unlikely as the underlying mechanism as both organs have the same histocompatibility antigens. Due to previous surgical complications and the need for reoperation, the patient declined another pancreas transplantation. It would have required at least two procedures, i.e., removal of the non-functioning pancreas and another pancreas transplantation. It would have been technically difficult and associated with an increased complication risk due to previous operations, multiple adhesions, and the long time that had passed since the previous transplantation. Pancreatic islet infusion to the liver via the portal vein system was not associated with any complications. Despite two infusion procedures, the patient did not become insulin-independent but benefited from improved hypoglycaemia awareness and reduction of the risk of hypoglycaemia episodes which impaired his daily life activities. Metabolic control also improved significantly, as evidenced by lower $\mathrm{HbA}_{1 c}$ levels and CGM parameters. Also of note, development of anti-HLA antibodies was not observed despite exposure to multiple incompatible HLA antigens with subsequent transplantations (kidney and pancreas transplantation 
followed by two pancreatic islet infusions. The function of the transplanted kidney remained stable and good, with no development of proteinuria. It was possible with proper immunosuppressive therapy resulting in adequate immunosuppressive drug levels protecting from both cellular and humoral rejection. The patient has been receiving the same immunosuppressive drugs since the simultaneous pancreas and kidney transplantation. As noted, drug doses were transiently increased and are currently being gradually reduced with the intent of returning to the dosage regimen used before pancreatic islet transplantation.

\section{Summary}

Pancreatic islet transplantation is a safe, minimally invasive procedure that is not associated with any significant burden for the patient. This management approach seems to be optimal particularly in kidney transplant recipients who already receive immunosuppressive therapy to prevent kidney transplant rejection, as the added risk for the patient is very small in this clinical setting. Pancreatic islet transplantation following kidney transplantation allows for stabilization of the clinical course of diabetes and minimization of the risk of life-threatening severe hypoglycaemia episodes.

\section{Conflict of interest}

The authors report no conflicts of interest.

\section{REFERENCES}

1. Gerber PA, Pavlicek V, Demartines N, et al. Simultaneous isletkidney vs pancreas-kidney transplantation in type 1 diabetes mellitus: a 5 year single centre follow-up. Diabetologia. 2008; 51(1): 110-119, doi: 10.1007/s00125-007-0860-4, indexed in Pubmed: 17973096.

2. Pedersen-Bjergaard U, Pramming S, Heller SR, et al. Severe hypoglycaemia in 1076 adult patients with type 1 diabetes: influence of risk markers and selection. Diabetes Metab Res Rev. 2004; 20(6): 479-486, doi: 10.1002/dmrr.482, indexed in Pubmed: 15386817.

3. Rickels $\mathrm{M}$, Stock $\mathrm{P}$, Koning Ede, et al. Defining Outcomes for $\beta$-cell Replacement Therapy in the Treatment of Diabetes: A Consensus Report on the Igls Criteria From the IPITA/EPITA Opinion Leaders Workshop. Transplantation. 2018; 102(9): 1479-1486, doi: 10.1097/tp.0000000000002158.

4. Benhamou PY, Milliat-Guittard L, Wojtusciszyn A, et al. GRAGIL group. Quality of life after islet transplantation: data from the GRAGIL 1 and 2 trials. Diabet Med. 2009; 26(6): 617-621, doi: 10.1111/j.1464-5491.2009.02731.x, indexed in Pubmed: 19538237.

5. Cure P, Pileggi A, Froud T, et al. Improved metabolic control and quality of life in seven patients with type 1 diabetes following islet after kidney transplantation. Transplantation. 2008; 85(6): 801-812, doi: 10.1097/TP.0b013e318166a27b, indexed in Pubmed: 18360260.

6. Grochowiecki T, Schmidt J. Leczenie immunosupresyjne po przeszczepianiu trzustki i wysp trzustkowych. In: Durlik M, Przybyłowski P, editors. Zalecenia dotyczące leczenia immunosupresyjnego po przeszczepieniu narządów unaczynionych. Warszawa: Fundacja Zjednoczeni dla Transplantacji. 2018: 130-142.

7. Wojtusciszyn A, Branchereau J, Esposito L, et al. TREPID group. Indications for islet or pancreatic transplantation: Statement of the TREPID working group on behalf of the Société francophone du diabète (SFD), Société francaise d'endocrinologie (SFE), Société francophone de transplantation (SFT) and Société française de néphrologie - dialyse - transplantation (SFNDT). Diabetes Metab. 2019; 45(3): 224-237, doi: 10.1016/j.diabet.2018.07.006, indexed in Pubmed: 30223084.

8. Lablanche S, Borot S, Wojtusciszyn A, et al. GRAGIL Network. Five-Year metabolic, functional, and safety results of patients with type 1 diabetes transplanted with allogenic islets within the SwissFrench GRAGIL network. Diabetes Care. 2015; 38(9): 1714-1722, doi: 10.2337/dc15-0094, indexed in Pubmed: 26068866. 